\title{
ANALYSIS FOR CONVERSION OF THE GEORGIA TECH RESEARCH REACTOR FROM HEU TO LEU FUEL*
}

ANE/EP/CP-77802

J.E. Matos, S.C. Mo, and W.L. Woodruff

DE93 002929

Argonne National Laboratory

Argonne, Illinois 60439-4841 USA

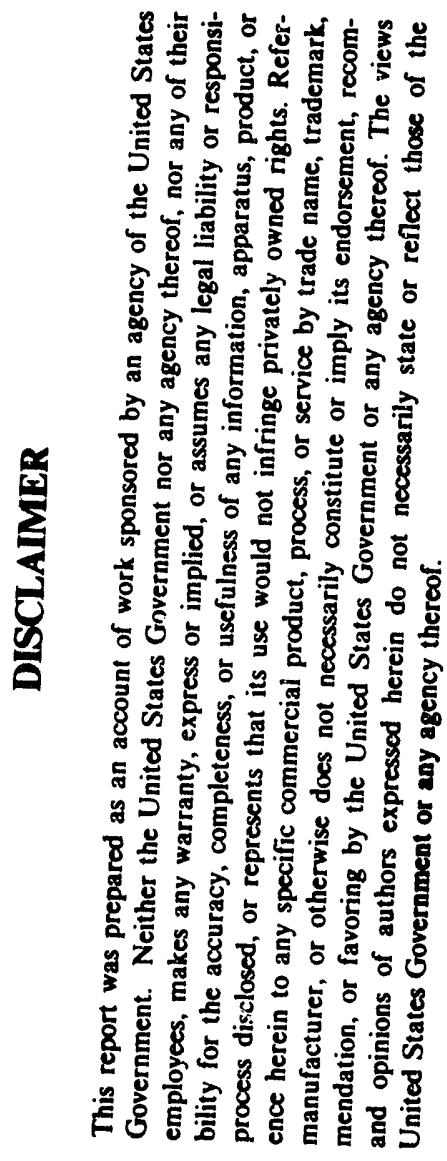

To be Presented at the

1992 International Meeting on

Reduced Enrichment for Research and Test Reactors

September 27-October 1, 1992

Roskilde, Denmark

The submitted manuscript has been authored
by a contractor of the U.S. Government
under contract No. W.31.109ENG.38.
Accordingly. the U. S. Government retains a
nonexclusive, royalty-free license to publish
or reproduce the published form of this
crntribution. or allow others to do so, for
$U . S$. Government purposes.

*Work supported by the U.S. Department of Energy,

Offi-e of Arms Control and Nonproliferation under Contract No. W31-109-ENG-38 


\title{
ANALYSES FOR CONVERSION OF THE GEORGIA TECH RESEARCH REACTOR FROM HEU TO LEU FUEL
}

\author{
J.E. Matos, S.C. Mo, and W.L. Woodruff \\ Argonne National Laboratory \\ Argonne, Ilinois, USA
}

\begin{abstract}
The 5 MW Georgia Tech Research Reactor (GTRR) is a heterogeneous, heavy water moderated and cooled reactor, fueled with highly-enriched uranium aluminum alloy fuel plates. The GTRR is required to convert to low enrichment (LEU) fuel in accordance with USNRC policy. Results of design and safety analyses performed by the RERTR Program at the Argonne National Laboratory for LEU conversion of the GTRR are summarized. Only those parameters which could change as a result of replacing the fuel are addressed. The performance of the reactor and all safety margins with LEU fiel are expected to be about the same as those with the current HEU fuel.
\end{abstract}

\section{INTRODUCTION}

The results of design and safety analyses performed by the RERTR Program at the Argonne National Laboratory for conversion of the Georgia Tech Research Reactor from the use of HEU fuel to the use of LEU fuel are presented. The objectives of this work were to: (1) maintain or improve upon the present reactor performance and margins of safety, (2) maintain as closely as possible the technical specifications and operating procedures of the present HEU core, and (3) utilize a proven fuel assembly design that is economical to manutacture.

The GTRR core contains provisions for up to 19 fuel assemblies spaced 6 inches apart in a triangular array. The fuel is centrally located in a six-foot diameter aluminum vessel which provides a two-foot thick $\mathrm{D}_{2} \mathrm{O}$ reflector completely surrounding the core. The vessel is surrounded radially and beneath by an additional two-foot thick graphite reflector. The reactor is controlled by means of four cadmium shim-safety blades that swing downward through the core between adjacent rows of fuel assemblies and one cadmium regulating rod that moves vertically in the radial $\mathrm{D}_{2} \mathrm{O}$ reflector. The reactor is equipped with 22 horizontal and 23 vertical experimental facilities for extracting neutron beams and performing irradiations. A shielded room (10 feet by 12 feet inside) for biomedical research is located at the side of the reactor.

The reactor performance objectives and design constraints that were addressed in designing the LEU fuel assembly are discussed in Ref. 1. The LEU fuel assembly has the same overall design as the present $\mathrm{HEU}$ fuel assembly, except that it contains 18 fueled plates with $\mathrm{LEU} \mathrm{U}_{3} \mathrm{Si}_{2}$ $\mathrm{Al}$ fuel and two non-fueled plates instead of 16 fueled plates with $\mathrm{HEU} \mathrm{U}-\mathrm{Al}$ alloy fuel and 2 non- 
fueled plates. Each HEU assembly contains $188 \mathrm{~g}{ }^{235} \mathrm{U}$ and each LEU assembly contains $225 \mathrm{~g}$ ${ }^{235} \mathrm{U}$. The LEU core will use the same control system, heat removal system, and auxiliary systems as the current HEU core.

\section{Reactor Models}

A detailed Monte Carlo model of the reactor was constructed including all beam tubes, experiment penetrations, the bio-medical facility, shim-safety blades, and regulating rod in order to obtain absolute excess reactivities and shutdown margins for comparison with limits specified in the Technical Specifications. The diffusion theory model did not include the control absorbers or the various experiment facilities. A simplified Monte Carlo model similar to the diffusion model was constructed to verify that the diffusion theory model was correct. Nuclear cross sections in seven energy groups were calculated using standard methods for use in the diffusion theory calculations.

\section{Critical Experiment}

In 1974, a critical experiment was built using 9 fresh HEU fuel assemblies. The core was made critical at different shim-safety blade positions with the regulating rod nearly fullywithdrawn and nearly fully-inserted. The excess reactivities calculated for these critical configurations using the detailed Monte Carlo model were $-0.91 \pm 0.20 \% \Delta \mathrm{k} / \mathrm{k}$ and $-1.22 \pm 0.22 \%$ $\Delta \mathrm{k} / \mathrm{k}$, respectively. The reactivity bias of about $-1.0 \pm 0.3 \% \Delta \mathrm{k} / \mathrm{k}$ in the calculations is attributed to uncertainties in the nuclear cross sections and uncertainties in the reactor materials.

\section{NEUTRONIC PARAMETERS}

\section{Excess Reactivity}

Cálculated excess reactivities (including reactivity bias) for fresh HEU and LEU cores with 17 fuel assemblies are shown in Table 1. The Technical Specifications limit the excess reactivity to a maximum of $11.9 \% \Delta \mathrm{k} / \mathrm{k}$. The LEU core is expected to satisfy this requirement.

Table 1. Excess Reactivities of HEU and LEU Cores with 17 Fresh Fuel Assemblies

\begin{tabular}{|c|c|c|}
\hline & $\begin{array}{l}\text { Calculated Exces } \\
\text { Eresh HEU Core }\end{array}$ & $\begin{array}{r}\text { React. }{ }^{1}, \% \Delta \mathrm{k} / \mathrm{k}( \pm 1 \sigma) \\
\text { Eresh LEU Core }\end{array}$ \\
\hline Detailed Monte Carlo Model & $11.7 \pm 0.4$ & $9.4 \pm 0.4$ \\
\hline $\begin{array}{l}\text { Simplified Monte Carlo Model}{ }^{2} \\
\text { Diffusion Theory Model }\end{array}$ & $\begin{array}{l}16.8 \pm 0.4 \\
16.6\end{array}$ & $\begin{array}{l}14.3 \pm 0.4 \\
14.6\end{array}$ \\
\hline
\end{tabular}

The reactivity bias of $-1.0 \pm 0.3 \% \Delta \mathrm{k} / \mathrm{k}$ was added to calculated values. ${ }^{2}$ Detailed Monte Carlo model without experiment penetrations, shim-safety blades, and regulating rod.

The reactivity effect of replacing all air-filled experiment facilities in the detailed Monte Carlo model with $\mathrm{D}_{2} \mathrm{O}$ or graphite was calculated to be $4.5 \pm 0.3 \% \Delta \mathrm{k} / \mathrm{k}$. Replacing the control absorbers in their fully-withdrawn position with $\mathrm{D}_{2} \mathrm{O}$ gave a worth consistent with zero. Thus, the simplified Monte Carlo and diffusion theory models are consistent with the detailed Monte Carlo model if the reactivity worth of the experiment facilities is accounted for. 


\section{Fuel Lifetimes}

Burnup calculations v're run for HEU and LEU cores with 17 fuel assemblies to estimate fuel lifetimes. Reactivity profiles (including the $1 \% \Delta \mathrm{k} / \mathrm{k}$ reactivity bias) are shown in Fig. 1 over a limited burnup range. The dashed lines show the end-of-cycle excess reactivity range that accounts for reactivity losses due to experiment facilities $(4.5 \pm 0.3 \% \Delta \mathrm{k} / \mathrm{k})$, cold-to-hot swing $(\sim 0.3 \% \Delta \mathrm{k} / \mathrm{k})$, and control provision $(\sim 0.5 \% \Delta \mathrm{k} / \mathrm{k})$ that are not included in the diffusion theory model. Reactivity losses due to equilibrium $\mathrm{Xe}$ and $\mathrm{Sm}$ are included in the curves. The results show that the HEU and LEU cores will have about the same lifetime.

Fig. 1. Burnup Reactivity Profiles

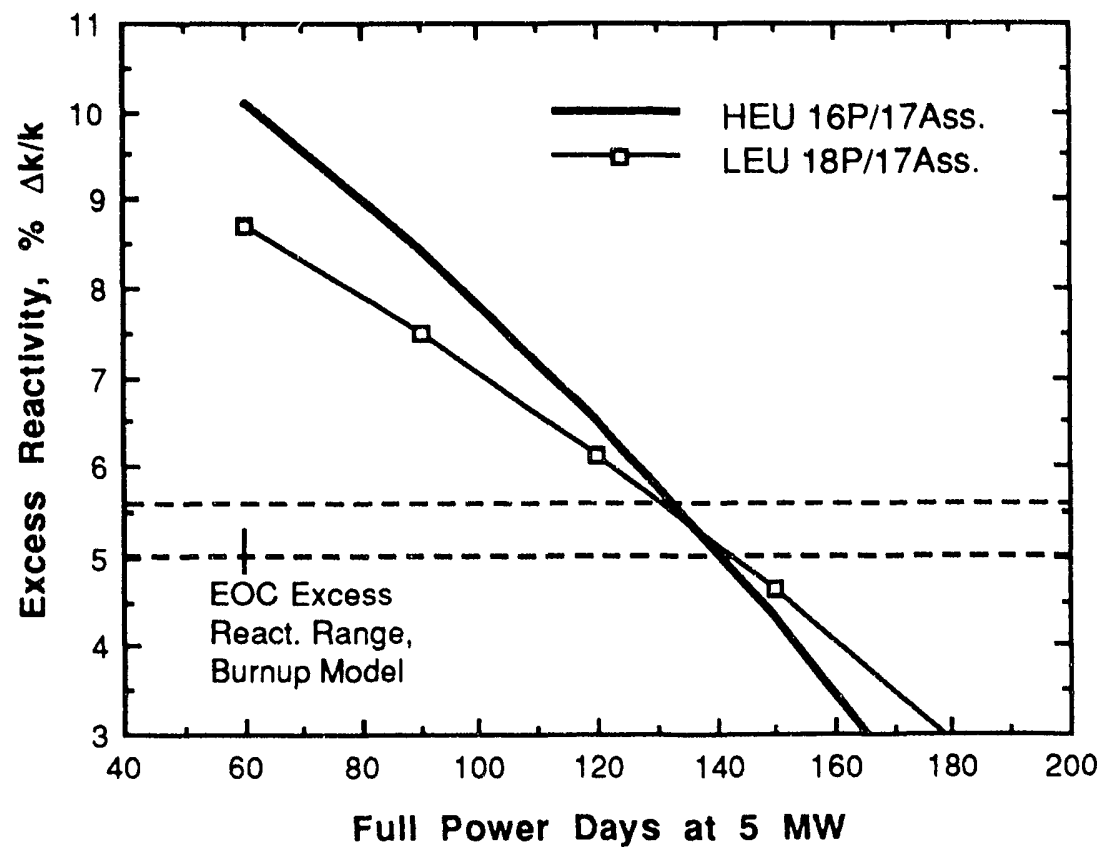

\section{Power Distributions and Power Peaking Factors}

Power distributions and nuclear power peaking factors were calculated to be very similar in HEU and LEU cores with 14 and 17 fresh fuel assemblies.

\section{Temperature Coefficients and Kinetics Parameters}

Reactivity coefficients for the coolant and the fuel Doppler were computed as functions of temperature for fresh HEU and LEU cores with 14 and 17 fuel assemblies. Also computed were the void coefficient, the whole-reactor isothermal temperature coefficient, and the prompt neutron lifetime. Fresh cores were calculated because they are limiting cores. As fuel burnup increases, the neutron spectrum becomes softer and the reactivity coefficients become more negative. Key temperature coefficients and kinetics parameters are summarized in Table 2. 
Table 2. Reactivity Coefficients $\left(\% \Delta \mathrm{k} / \mathrm{k}^{\circ} \mathrm{C}\right.$ at $\left.45^{\circ} \mathrm{C}\right)$ and Kinetics Parameters

\begin{tabular}{lcccc} 
& \multicolumn{2}{c}{ HEU } & \multicolumn{2}{c}{ LEU } \\
& 14 Ass. & 17 Ass. & 14 Ass. & 17 Ass. \\
Coolant & -0.0076 & -0.0069 & -0.0067 & -0.0066 \\
Fuel Doppler & -0.0 & $\sim 0.0$ & -0.0017 & -0.0020 \\
Whole Reactor Isothermal1 $^{1}$ & -0.0224 & -0.0201 & -0.0232 & -0.0215 \\
Void Coefficient $^{2}$ & -0.0383 & -0.0392 & -0.0333 & -0.0350 \\
Ip $^{3}, \mu$ s & 780 & 704 & 745 & 695 \\
$\beta_{\text {eff }}$ & $0.00755^{4}$ & $0.00755^{4}$ & $0.0075-0.0076^{5}$
\end{tabular}

1 Includes fuel, coolant, inter-assembly water, and reflector. $2 \% \Delta \mathrm{k} / \mathrm{k} / \%$ Void. Uniform voiding of coolant in all fuel assemblies. ${ }^{3}$ Calculated prompt neutron lifetime. ${ }^{4}$ Measured effective delayed neutron fraction. ${ }^{5}$ Estimated value.

\section{Shutdown Margins}

The Technical Specifications require that the reactor have a shutdown margin of at least $1 \%$ $\Delta \mathrm{k} / \mathrm{k}$ with the most reactive shim-safety blade (blade \#3) and the regulating rod fully withdrawn. Shutdown margins calculated using the detailed Monte Carlo model gave $-7.1 \pm 0.2 \% \Delta \mathrm{k} / \mathrm{k}$ for an HEU core and $-8.8 \pm 0.2 \% \Delta k / k$ for an LEU core with 17 fresh fuel assemblies. Both cores satisfy the shutdown margin requirement.

In addition to the automatic protective systems, manual scram and reflector drain provide backup methods to shut the reactor down by operator action. Results of Monte Carlo calculations with shim-safety blade positions that would bring the reactor near critical are shown in Table 3 . These results show that the top reflector worth of the LEU core is slightly larger than that of the HEU core.

Table 3. Calculated Top Reflector Worths (\% $\% \mathrm{k} / \mathrm{k})$ of HEU and LEU Cores with 17 Fuel Assemblies and Control Blades near CriticalPositions

Iop $\mathrm{D}_{2} \mathrm{O}$ Reflecter
$\mathrm{D}_{2} \mathrm{O}$ 1" Above Fuel Meat
$\mathrm{D}_{2} \mathrm{O}$ 2" Above Fuel Meat

\section{HEU Core}

$-2.58 \pm 0.29(1 \sigma)$

$-2.05 \pm 0.28$

\section{LEU Core}

$-2.73 \pm 0.31(1 \sigma)$

$-2.42 \pm 0.30$

\section{THERMAL-HYDRAULIC SAFETY PARAMETERS}

Thermal-hydraulic safety limits and safety margins calculated using the PLTEMP code $^{2}$ for the LEU core with 14 fuel assemblies were compared with the thermal-hydraulic safety parameters used as bases for the current Technical Specificatiors. ANL analyses for the LEU core used a combined multiplicative and statistical treatment of a revised set of engineering uncertainty factors. Results for the HEU core obtained using ANL's statistical treatment agree well with the original analyses performed by Georgia Tech. The modified Wheatherhead correlation ${ }^{3}$ was used for departure from nucleate boiling (DNB), the Forgan-Whittle correlation ${ }^{4}$ was used for flow instability, and the Bergles and Rohsenow correlation ${ }^{5}$ was used for onset of nucleate boiling (ONB). 


\section{Safety Limits}

Calculated reactor power limits based on DNB and flow instability are shown in Table 4 for 14-assembly HEU ard LEU cores with the minimum coolant flow of $1625 \mathrm{gpm}$ and with the coolant lowflow linit of $760 \mathrm{gpm}$. Power limits based on the flow instability criterion are adequate to ensure the safety of the facility. The main reason for differences between the HEU and LEU cores is that the manufacturing specifications for LEU silicide dispersior fuel plates contain a factor of 1.2 for homogeneity of the fuel distribution while the HEU alloy fuel has a corresponding factor of 1.03 .

Table 4. Reactor Power Limits (MW) in 14-Assembly Cores Based on DNB and Flow Instability for a Maximum Inlet Temperature of $50.5^{\circ} \mathrm{C}$.

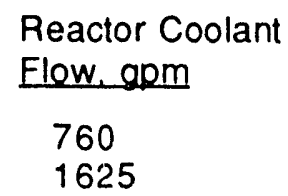

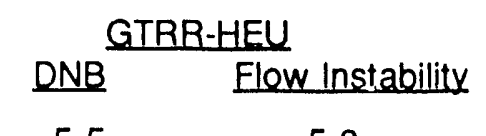

\begin{tabular}{cc}
\multicolumn{2}{c}{ ANL-LEU } \\
DNB & Flow Instability \\
5.3 & 5.0 \\
10.8 & 10.6
\end{tabular}

Safety limits for the reactor inlet temperature were calculated at the maximum reactor power of $5.5 \mathrm{MW}$ and the minimum coolant flow of $1625 \mathrm{gpm}$. The results are shown in Table 5. A safety limit for the reactor outlet temperature was then established by adding the average temperature rise across the core to the limiting inlet temperature. These results show that the HEU and LEU cores have nearly identical safety limits on the reactor inlet and oulet temperatures.

Table 5. Safety Limits on Reactor Inlet and Outlet Temperatures.

\section{Parameter}

Limiting Reactor Inlet Temp., ${ }^{\circ} \mathrm{C}$

Ave. Coolant Temp. Rise across Core, ${ }^{\circ} \mathrm{C}$

Limiting Fleactor Outlet Temp., ${ }^{\circ} \mathrm{C}$

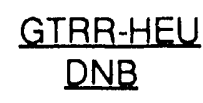

77.8

8.9

86.7

\begin{tabular}{rc}
\multicolumn{2}{c}{ ANL-LEU } \\
DNB & Flow Instability \\
77.2 & 76.7 \\
9.4 & 9.4 \\
86.6 & 86.1
\end{tabular}

\section{Safety System Trip Settings}

The safety system trip settings in the current GTRR Technical Specifications for power levels $>1 \mathrm{MW}$ and the nominal value for each parameter are shown in Table 6 .

Table 6. Current Safety System Trip Settings for Power Levels $>1 \mathrm{MW}$.

\begin{tabular}{lcr} 
Parameter & $\begin{array}{c}\text { Trip } \\
\text { Setting }\end{array}$ & $\begin{array}{r}\text { Nominal } \\
\text { Value }\end{array}$ \\
\cline { 2 - 3 } Thermal Power, MW & 5.5 & 5.0 \\
Reactor Coolant Flow, gpm & 1625 & 1800 \\
Reactor Outlet Temperature, ${ }^{\circ} \mathrm{C}$ & 59.4 & 54.4
\end{tabular}

These settings are based on a criterion that there shall be no incipient boiling during normal operation. The criterion is applied in GTRR by ensuring that the surface temperature at any point on a fuel assembly does not exceed the coolant saturation temperature at that point. This criterion 
is conservative because there is an additional margin of $\sim 14^{\circ} \mathrm{C}$ between the $\mathrm{D}_{2} \mathrm{O}$ saturation temperature and the temperature at which onset of nucleate boiling occurs.

Combinations of reactor power, coolant flow rate, and reactor inlet temperature that were calculated to have zero subcooling (fuel surface temperature $=$ coolant saturation temperature) for HEU and LEU cores with 14 fuel assemblies are shown in Table 7. Underlined values for the HEU core correspond with the trip settings shown in Table 6 . Corresponding underlined values for the LEU core were determined to be more conservative than those for the HEU core. Thus, the current trip settings for the HEU core can also be used for the LEU core.

Table 7. Parameter Combinations for Zero Subcooling with i4-Assembly Cores

HEU Core

Reactor Power, MW

Coolant Flow Rate, gpm

Reactor Inlet Temp., ${ }^{\circ} \mathrm{C}$

Temp. Rise Across Core, ${ }^{\circ} \mathrm{C}$

Reactor outlet Temp., ${ }^{\circ} \mathrm{C}$

$\begin{array}{rrr}5.5 & 5.0 & 5.0 \\ 1800 & 1625 & 1800 \\ 45.6 & 45.6 & 50.5 \\ 8.9 & 8.9 & 8.9 \\ 54.4 & 54.4 & \underline{59.4}\end{array}$

LEU Core

$\begin{array}{rrr}5.6 & 5.0 & 5.0 \\ 1800 & <1625 & 1800 \\ 45.6 & 45.6 & 53.3 \\ 9.4 & 9.4 & 9.4 \\ 55.0 & 55.0 & 62.7\end{array}$

The results in Table 8 show that the degree of subcooling $\left(\Delta \mathrm{T}_{\text {sub }}\right)$ at the hottest spot of the limiting fuel assembly under nominal operating conditions is expected to be $6.1^{\circ} \mathrm{C}$ in the LEU core and $4.4^{\circ} \mathrm{C}$ in the HEU core. Both of these margins are adequate. Another criterion that is often used in research reactors is that the margin to onset of nucleate boiling (ONB) should be equal to or greater than 1.2. ONB occurs at a temperature of about $118.9^{\circ} \mathrm{C}$, which is $\sim 14^{\circ} \mathrm{C}$ above the $\mathrm{D}_{2} \mathrm{O}$ saturation temperature of $104.4^{\circ} \mathrm{C}$. The margin to ONB in the LEU core was computed by increasing the reactor power until ONB occured and dividing by the nominal reactor power of 5 MW. These margins are adequate to ensure that the LEU core can be operated safely at a power levels of 1-5 MW.

Table 8. Margins to $D_{2} O$ Saturation Temperature and ONB for 14-Assembly Cores

Parameter

Thermal Power, MW

Reactor Coolant Flow, gpm

Reactor Inlet Temp., ${ }^{\circ} \mathrm{C}$

$\Delta T_{\text {sub }}{ }^{\circ} \mathrm{C}$

Margin to ONB

Limiting Power Based on ONB, MW

\section{GTRR-HEU}

5.0

180.0

45.6

4.4
ANL-LEU

5.0

1800

45.6

6.1

1.44

7.2 


\section{ACCIDENT ANALYSES}

A spectrum of accident scenarios was evaluated by Georgia Tech in its safety documentation for $5 \mathrm{MW}$ operation using HEU fuel. These scenarios were thoroughly reviewed and only those that could be affected by changing the fuel assemblies from HEU to LEU were addressed.

\section{Startup Accident}

The worst case for a possible startup accident in the current HEU core was determined to result from the simultaneous withdrawal of one shim blade and the regulating rod. Calculations were done using the PARET code ${ }^{6}$ for the HEU and LEU cores with 14 fuel assemblies in which reactivity was added at a rate of $0.005 \Delta \mathrm{k} / \mathrm{k}$ per second starting from a power level of $5 \mathrm{MW}$. Both the HEU and LEU cores were scrammed by the overpower trip at $5.5 \mathrm{MW}$. A time delay of $100 \mathrm{~ms}$ was assumed between introduction of the scram signal and release of the shim-safety blades. Both cores reached a peak power of $5.9 \mathrm{MW}$ at a time of $0.335 \mathrm{~s}$ after the transient was initiated. Peak surface cladding temperatures of $80.6^{\circ} \mathrm{C}$ and $77.8^{\circ} \mathrm{C}$ were reached in the limiting fuel assembly of the HEU and LEU cores, respectively. The peak power is well below the safety limits of $11.5 \mathrm{MW}$ in the HEU core and $10.6 \mathrm{MW}$ in the LEU core. The peak surface cladding temperatures are far below the solidus temperature of $660^{\circ} \mathrm{C}$ in the $1100 \mathrm{Al}$ cladding of the HEU core and far below the solidus temperature of $582^{\circ} \mathrm{C}$ in the $6061 \mathrm{Al}$ cladding of the LEU core. Thus, no damage to the fuel and no release of fission products is expected.

\section{Inadvertent Reactivity Insertions Due to Experiment Failure (with Scram)}

The Technical Specifications limit the magnitude of the reactivity worth of each unsecured experiment to $0.4 \% \Delta \mathrm{k} / \mathrm{k}$ and the reactivity worth of each secured removable experiment to $1.5 \%$ $\Delta \mathrm{k} / \mathrm{k}$. The objective of these specifications is to prevent damage to the reactor and to limit radiation dose to personnel and the public in event of experiment failure.

The PARET code was used to calculate the consequences of inadvertent step reactivity insertions of $0.4 \% \Delta \mathrm{k} / \mathrm{k}$ and $1.5 \% \Delta \mathrm{k} / \mathrm{k}$ in HEU and LEU cores with 14 fuel assemblies. The model and methods that were used for analysis of the SPERT-II BD-22/24 HEU core ${ }^{7,8}$ were also used to analyze the HEU and LEU cores of the GTRR. Temperature coefficients included contributions from only the coolant and the fuel. Calculations were performed with the reactor at nominal operating conditions of $5 \mathrm{MW}$ power, a coolant flow rate of $1800 \mathrm{gpm}$, and a reactor inlet temperature of $45.6^{\circ} \mathrm{C}$. A scram signal was initiated when the reactor power reached the safety system overpower trip setting of $5.5 \mathrm{MW}$. A time delay of $100 \mathrm{~ms}$ was assumed between introduction of the scram signal and release of the shim-safety blades. The results of these calculations are shown in Table 9.

Table 9. Results of Assumed Step Reactivity Insertions Due to Experiment Failure (with Scrarn)

\author{
Parameter \\ Step Reactivity Insertion, \% $\Delta \mathrm{k} / \mathrm{k}$ \\ Asymptotic Period, s \\ Peak Power, MW \\ Peak Surface Cladding Temp., ${ }^{\circ} \mathrm{C}$
}

\begin{tabular}{rr}
\multicolumn{2}{c}{ HEU Core } \\
0.4 & 1.5 \\
0.18 & 0.05 \\
7.4 & 27.5 \\
84.4 & 136.1
\end{tabular}

1.5

27.5

36.1

\begin{tabular}{rr}
\multicolumn{2}{c}{ LEU Core } \\
0.4 & 1.5 \\
0.18 & 0.05 \\
7.4 & 27.2 \\
81.7 & 130.6
\end{tabular}


A positive step reactivity change less than $0.4 \% \Delta \mathrm{k} / \mathrm{k}$ caused by the ejection or insertion of experiments would result in transient behavior that would not exceed the safety limits for the HEU or LEU cores. The peak power of $7.4 \mathrm{MW}$ in both cores is well below the safety limits of 11.5 MW in the HEU core and $10.6 \mathrm{MW}$ in the LEU core.

Step reactivty insertions of $1.5 \% \Delta \mathrm{k} / \mathrm{k}$ would result in peak surface cladiling temperatures that are far below the solidus temperature of $660^{\circ} \mathrm{C}$ in the $1100 \mathrm{Al}$ cladding of the HEU core and far below the solidus temperature of $582^{\circ} \mathrm{C}$ in the $6061 \mathrm{Al}$ cladding of the LEU core. Thus, no damage to the fuel and no release of fission products is expected.

\section{Maximum Positive Reactivity Insertion Without Scram}

The Technical Specifications limit the potential reactivity worth of each secured removable experiment to $1.5 \% \Delta \mathrm{k} / \mathrm{k}$. The purpose of this analysis is to show that there is a sufficient margin between the maximum allowable reactivity worth of a single experiment and the maximur itep reactivity insertion that can be tolerated without fuel damage, assuming failure of reactor $s$ am systems.

Analysis for the current HEU core used SPERT-II experimental data ${ }^{8}$ as a basis for estimating the step reactivity insertion that would result in the onset of steam blanketing in the GTRR. In the present analysis, the PARET code wis used to compute the step reactivity insertion required to initiate steam blanketing (film boiling) in both the SPERT-II B22/24 core and 14 assembly GTRR cores with HEU and LEU fuel. Key kinetics parameters and results are shown in Table 10. Power peaking factors are similar in the SPERT-II and GTRR cores. The inverse period corresponding to onset of steam blanketing as determined from the SPERT data is about 13 $\mathrm{s}^{-1}$. The PARET code predicts onset of film boiling for a step insertion of $\$ 2.0(1.5 \% \Delta \mathrm{k} / \mathrm{k})$ with an inverse period of $12 \mathrm{~s}^{-1}$, in good a rreement with experiment.

Table 1n. Comparison of Kinetics Parameters and Onset of Steam Blanketing Results

\begin{tabular}{lccc} 
& SPERT-ll & \multicolumn{2}{c}{14 Assembly GTRR } \\
& B-22/24 & HEU & LEU \\
Prompt Neutron Generation Time, $\mu \mathrm{s}$ & 660 & 780 & 745 \\
Beta Effective & 0.0075 & 0.00755 & 0.00755 \\
Coolant Temperture Coeff., $\$ /{ }^{\circ} \mathrm{C}$ & -0.00867 & -0.00874 & -0.00689 \\
Void Coefficient, $\$ / \%$ Void & -0.0729 & -0.0509 & -0.0442 \\
Doppler Coefficient, $\$ /{ }^{\circ} \mathrm{C}$ & -0.0 & $\sim 0.0$ & -0.00096 \\
Operating Pressure, $\mathrm{kPa}$ & 122 & 127 & 127 \\
Step Reactivity Insertion, $\$(\% \Delta \mathrm{k} / \mathrm{k})$ & 2.00 & 1.99 & 1.95 \\
Inverse Period, $\mathrm{s}^{-1}$ & 12 & 19 & 19 \\
Energy/Plate at tm, $\mathrm{kWs}$ & 31.8 & 31.2 & 32.0 \\
Peak Cladding Temp at Peak Power, ${ }^{\circ} \mathrm{C}$ & 204 & 218 & 225 \\
Peak Cladding Temperature at & 252 & 257 & 257 \\
Onset of Steam Blanketing, ${ }^{\circ} \mathrm{C}$ & & &
\end{tabular}


The same methodology was used to compute GTRR cores with 14 fuel assemblies. The step insertions reeded to initiate film boiling $(\sim 2.0)$ and the peak surface cladding temperatures (250$260^{\circ} \mathrm{C}$ ) at the onset of steam blanketing are nearly the same. At the time of peak power, the energy deposited per plate is about the same in the SPERT and GTRR cores. The peak surface cladding temperature at the time of peak power is about $220^{\circ} \mathrm{C}$ in the GTRR cores and about $204^{\circ} \mathrm{C}$ in the SPERT core.

The SPERT-II B22/24 tests 8 indicate that even more extensive film boiling (or steam blanketing) does not result in temperatures that exceed the solidus temperature of the cladding. The most extreme case in the test series with a reactivity insertion of $\$ 2.95(2.2 \% \Delta \mathrm{k} / \mathrm{k})$ resulted in a peak surface cladding temperature of $337^{\circ} \mathrm{C}, \mathrm{s}$ temperature far below the solidus temperature of $582^{\circ} \mathrm{C}$ for $6061 \mathrm{Al}$ cladding. The GTRR SAR also notes that the maximum temperature for large insertions is primarily limited by the energy deposited in the plate with very little effect from the boiling heat transfer.

Since the behavior of the SPERT-II B22/24 and GTRR 14-assembly cores is very similar, a step reactivity insertion greater than $2.2 \% \Delta \mathrm{k} / \mathrm{k}$ would be required to initiate melting of the GTRR LEU core. The margin of at least $0.7 \% \Delta \mathrm{k} / \mathrm{k}$ above the maximum allowed reactivity worth of $1.5 \% \Delta \mathrm{k} / \mathrm{k}$ for a single experiment is sufficient to ensure that the facility is safe in the unlikely event that the maximum allowed reactivity were inserted in a step and the reactor scram system failed to function.

\section{Design Basis Accident}

The Design Basis Accident for the HEU core in the GTRR safety documentation is the melting and release of the fission products from one fuel assembly into the containment atmosphere. This accident was assumed to occur during a fuel transfer operation in which an irradiated fuel assembly was being moved from the core to the fuel storage area using a shielded transfer cask. Fuel assemblies are not normally discharged from the reactor until at least 12 hours after reactor shutdown. This ensures that sufficient fission product decay heat has been removed from the assembly and that the surface temperature of the fuel plates will not reach $450^{\circ} \mathrm{C}$ when the assembly is moved into the cask.

In spite of administrative controls, it is conceivable that a fuel assembly could be withdrawn from the reactor prior to a 12 hour cooldown period. Some or all of the fuel plates within the assembly could then melt and release some of their fission products into the containment atmosphere. In the current GTRR SAR, the source term for evaluating the radiological consequences of this accident was obtained by assuming that an HEU fuel assembly with equilibrium burnup was removed from the core before the 12 hour cooldown period. All of the plates in the fuel assembly melt and the isotopes of iodine, krypton, and xenon were released to the containment. The limiting dose is the thyroid dose from the icdine isotopes.

Since the HEU and LEU cores operate at $5 \mathrm{MW}$, neutron flux levels and equilibrium concentrations of iodine, xenon, and krypton will be about the same in the two cores. From burnup calculation results shown in Fig. 1, it was concluded that the lifetimes of the HEU and 
LEU core will be about the same. As a result, concentrations of the other fission products in the LEU and HEU fuel assemblies will be very similar. The exception is that the LEU assembly will contain larger concentrations of plutonium isotopes. Reference 9 contains a detailed analysis comparing the radiological consequences of a hypothetical accident in a generic $10 \mathrm{MW}$ reactor using HEU and LEU fuels. This analysis concluded that the buildup of plutonium in discharge fuel assemblies with ${ }^{235} \mathrm{U}$ burnup of over $50 \%$ does not significantly increase the radiological consequences over those of HEU fuel. Because fission product concentrations in the GTRR HEU and LEU cores are expected to be comparable, the thyroid dose shown in the GTRR SAR for HEU fuel will be the limiting dose for both cores.

\section{COOLING TIME REQUIREMENTS}

The primary coolant pumps must be operated for 8 hours following operation at power levels of more than $1 \mathrm{MW}$ to preclude the possibility of fuel plate melting in the event of a loss-ofcoolant accident following reactor shutdown. In addition, a minimum cooldown time of twelve hours is required before fuel assemblies are transferred out of the reactor. A limit of $450^{\circ} \mathrm{C}$ was set in the Technical Specifications as the upper limit for a fuel plate temperature to preclude melting of the plates.

The analysis method followed the superposition technique used in the GTRR safety documentation for the HEU core, with modification of the input parameters appropriate for the LEU fuel assembly design. The most important modification was that the maximum power per fuel plate in the LEU assembly was reduced by a factor of 16/18 since an HEU assembly contains 16 fueled plates and an LEU assembly contains 18 fueled plates. A standard 3-week operating history consisting of 4.3 days at full power of $5 \mathrm{MW}$ and 2.7 days shutdown was used for 14 assembly cores with HEU and LEU fuel.

The results for loss-of-coolant from the reactor vessel after eight hours of cooling gave a maximum plate temperature of $425^{\circ} \mathrm{C}$ in the HEU core and $400^{\circ} \mathrm{C}$ in the LEU core. The maximum temperature occurred 45 minutes after loss-of-coolant in the HEU core and 50 minutes after loss-of-coolant in the LEU core. Thus, the surrent Technical Specification requirements on cooling times are more conservative for the LEU core than for the HEU core.

\section{FUEL HANDLING AND STORAGE}

The objective of the Technical Specifications that apply to the handling and storage of fuel assemblies is to prevent inadvertent criticality outside of the reactor vessel and to prevent overheating of irradiated fuel assemblies.

Irradiated fuel assemblies are stored in aluminum racks fastened to the side walls of a light water pool. There is one rack along each of the two walls and each rack can accomodate up to 20 
assemblies in a linear array. The center-to-center spacing of the assemblies is six inches and the separation between assemblies is about three inches.

A systematic nuclear criticality assessment ${ }^{10}$ been done for infinite-by-infinite arrays of fresh LEU fuel assemblies with ${ }^{235} \mathrm{U}$ contents between 225 and 621 grams using the ORR fuel storage rack spacing specifications ${ }^{11}$ of 0.7 inch assembly separation and 6.8 inch row separation. An assembly similar to the GTRR LEU assembly with a ${ }^{235} \mathrm{U}$ content of 225 grams gave a $\mathrm{k}_{\text {eff }}$ of 0.72 , well below the maximum $k_{\text {fff }}$ of 0.85 needed to ensure an adequate margin below criticality for storage of irradiated fuel assemblies. The GTRR storage configuration discussed above will have $k_{\text {eff }}$ less than 0.72 .

Currently, no more than four unirradiated HEU fuel assemblies can be together in any one room outside the reactor, shipping container, or fuel storage racks. Calculations of HEU and LEU cores indicate that a grouping of four LEU assemblies will be less reactive than the same configuration of HEU assemblies. Thus, the current specification will also hold for LEU fuel.

\section{CONCLUSION}

Conversion of the GTRR core from HEU to LEU fuel is feasible utilizing an LEU assembly containing 18 DOE standard silicide fuel plates (for university MTR-type reactors) as a replacement for the current HEU assembly with 16 fueled plates. Both HEU and LEU assemblies contain two unfueled outer plates to form an enclosed flow volume. The LEU assemblies would contain $225 \mathrm{~g}{ }^{235} \mathrm{U}$ instead of $188 \mathrm{~g}{ }^{235} \mathrm{U}$ in the current HEU assemblies.

Calculations shown in Ref.1 indicate that the epithermal flux at the bio-medical facility will be slightly larger in the LEU core. The lifetime of the LEU core is expected to be about the same as that of the HEU core. All safety margins with the LEU fuel are very similar to t'.tose with the current HEU fuel and are adequate to ensure the safety of the facility. 


\section{REFERENCES}

1. R.A. Karam, J.E. Matos, S.C. Mo, and W.L. Woodruff, "Status Report on Conversion of the Georgia Tech Research Reactor to Low Enrichment Fuel," Proc. 1991 International Meeting on Reduced Enrichment for Research and Test Reactors, Jakarta, Indonesia, 4-7 November 1991 (to be published)

2. K. Mishima and T. Shibata, "Thermal-hydraulic Calculations for KUHFR with Reduced Enrichment Uranium Fuel," KURRI-TR-223 (1982), and K. Mishima, K. Kanda, and T. Shibata, "Thermal-hydraulic Analysis for Core Conversion to Use of Low-enriched Uranium Fuels in the KUR," KURRI-TR-258 (1984).

3. R. J. Weatherhead, "Nucleate Boiling Characteristics and the Critical Heat Flux Occurrence in Subcooled A::ial-Flow Water Systems," ANL-6674, 1963.

4. R. H. Whittle and R. Forgan, "A Correlation for the Minima in the Pressure Drop Versus Flow-Rate Curves for Subcooled Water Flowing in Narrow Heated Channels," Nuclear Engineering and Design, Vol. 6, (1967) pp. 89-99. "Guidebook on Research Reactor Core Conversion from the Use of Highly Enriched Uranium to the Use of Low Enriched Uranium Fuels", IAEA-TECDOC-233 (1980) pp. 99-106.

5. A.E. Bergles and W.M. Rohsenow, "The Determination of Forced-Convection SurfaceBoiling Heat Transfers," Transactions of the ASME $\underline{86}$ (Series C - Journal of Heat Transfer), pp. 365-371 (August 1964).

6. C.F. Obenchain, "PARET - A Program for the Analysis of Reactor Transients," IDO17282, Idaho National Engineering Laboratory (1969).

7. W. L. Woodruff, "Additional Capabilities and Benchmarking with the SPERT Transients for Heavy Water Applications of the PARET Code," Proc. XIIth International Meeting on Reduced Enrichment for Research and Test Reactors, Berlin, 10.-14. September 1989., Konferenzen des Forschungs-zentrums Jülich(1991).

8. J. E. Grund, "Self-Limiting Excursion Tests of a Highly Enriched Plate-Type D2OModerated Reactor, Part I. Initial Test Series", USAEC Report IDO-16891, Phillips Petroleum Co., July 12, 1963.

9. W.L. Woodruff, D.K. Warinner, and J.E. Matos, "A Radiological Consequence Analysis with HEU and LEU Fuels," Proc. 1984 International Meeting on Reduced Enrichment for Research and Test Reactors, Argonne National Laboratory, Argonne, IL, October 15-18, 1984, ANL/RERTR/TM-6, CONF-8410173, pp. 472-490 (July 1985).

10. R.B. Pond and J.E. Matos, "Nuclear Criticality Assessment of LEU and HEU Fuel Element Storage," Proc. 1983 International Meeting on Reduced Enrichment for Research and Test Reactors, Japan Atomic Energy Research Institute, Tokai, Japan, October 24-27, 1983, JAERI-M 84-073, pp. 416-425 (May 1984).

11. J.T. Thomas, "Nuclear Criticality Assessment of Oak Ridge Research Reactor Fuel Element Storage," ORNL/CSD/TM-58, Oak Ridge National Laboratory (1978). 

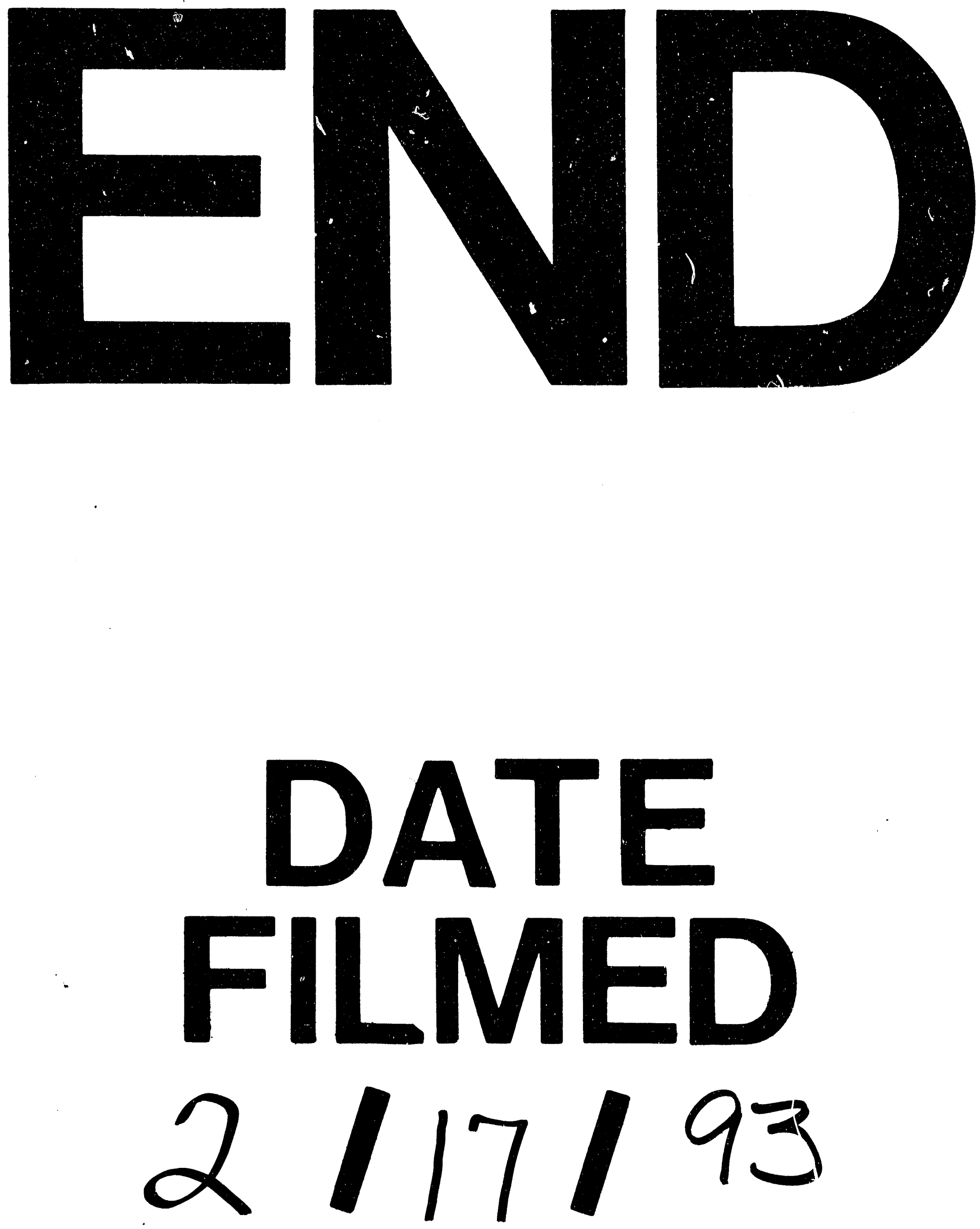
